\title{
Comprehending Smiles Seldom Requires Embodied Simulation and Felt Emotion
}

\author{
Vladimir J. Konečni*
}

Department of Psychology, University of California, San Diego, La Jolla, California 92093-0109, USA

\begin{abstract}
The Simulation of Smiles Model (SIMS; Niedenthal, Mermillod, Maringer, \& Hess, 2010), based on "embodied simulation," is contrived and of low ecological applicability, marshaling a seldom-used route for the comprehension and classification of smiles. Moreover, the tripartite division of smiles, for which the model has been developed, is of limited sociobiological importance. Genuineness of facial expressions should remain the central problem in this research area. Additional discussion is devoted to the relationship of dominance smiles to the experience of awe.
\end{abstract}

Keywords: Smile; Embodied simulation; SIMS; Dominance smile; Recognition of emotion; Felt emotion; Awe

From an evolutionary perspective, it seems clear that the key decision of a perceiver $(\mathrm{P})$ regarding a sender's $(\mathrm{S})$ smile is whether the smile is genuine or false (based on the Duchenne marker and postural, contextual, and experiential cues). Past analyses of smiles have rightly recognized this and the "revisionist" dismissal of the true-false smile distinction by $[1$, p. 419] is not convincing on either conceptual or evidentiary grounds; nor is their claim that a more useful distinction is one between positive-affect, positive-intention, and dominance smiles. With regard to P's important biological concerns, distinguishing between S's positive-affect and positive-intention smiles is a relatively minor issue, and as for dominance smiles, $\mathrm{P}$ needs additional contextual information to conclude confidently, "S has demonstrable dominance over me" - instead of, for example, "S is bluffing in an attempt to dominate me." (The case where $S$ is known to have high status and emits an apparently positive-intention smile is interesting, but it is essentially a true-false problem.) In short, the tripartite division of smiles by [1] makes little sociobiological sense - and yet the Simulation of Smiles Model (SIMS) has apparently been developed specifically to deal with this trichotomy.

The model is cumbersome and contrived. One of its significant problems is low ecological applicability. If the genuineness of smiles is not in the model's domain, and the classification of a facial expression as a dominance smile requires additional information, how often would making the correct distinction among the members of the tripartition require P's embodied simulation of S's state - and his or her production of changes in no less than four systems (motor, somatosensory, affective, and reward)? P's repeated engagement in the activities proposed by the SIMS model seems to be a frivolous waste of resources. How sensible would it be for $\mathrm{P}$ to be shaped by adaptive pressures in such a way that all of these operations are "triggered" (p. 418) by someone's smile? [1] apparently believe that adult humans have to work hard (ceaselessly mimicking and experiencing, unconsciously or not) to accomplish the rather mundane task of comprehension of others' benign facial expressions. For a human to respond emotionally and experience pleasure to each encountered smile borders on the absurd - yet there is no discussion in the article about which smiles (genuine or not) matter.

Actually, there is some discussion, but it is limited to the claim that eye contact "modulates" the occurrence of "embodied simulation" ( $p$. 425) or (automatically?) "triggers" it (p. 425) when P views S's smile. Note that eye contact is far more likely in one-on-one situations than when $\mathrm{P}$ observes a potential "sender of smiles" in a group setting which means that the probability of SIMS being of any consequence in the comprehension of smiles is further limited, mostly to face-toface encounters. Also, oddly, [1, p. 425] discuss the relationship of eye contact and intimacy as if it supports their hypothesis of an increased probability of occurrence of simulation in intimate relationships, when it is obvious that it is precisely in intimate, long-term relationships, with numerous and frequent face-to-face encounters, that $\mathrm{P}$ does not need to simulate S's state in order to evaluate S's smile. And if $\mathrm{P}$ were to simulate it, it might be more likely due to P's desire to communicate back to $S$ more fully - perhaps to express gladness about S's gladness - than in order to comprehend and classify S's smile.

Empirical basis for many aspects of SIMS is lacking. For example, to support the notion that eye contact "triggers an embodied simulation" (p. 425), Niedenthal et al. [1] cite - on the same page and somewhat misleadingly - the study by [2], which not only dealt with P's mimicking of S's facial expression of pain, but also produced results that were rather ambiguous even without being used as support for SIMS. The implications of several experiments are assimilated rather uncritically. In at least one case, involving research participants biting a pencil while watching numerous "morphed faces" (that allegedly portrayed "emotion"), [1] assume that the recognition results were due to the "spontaneous expression [being] blocked by mechanical means" (p. 431; italics added).

By no means should this commentary be interpreted as saying that people do not sometimes mimic others' facial expressions, consciously and unconsciously. This may occur spontaneously in real life or upon being instructed to mimic in experiments. It may be visible to the naked eye or the micro facial movements may be observable only electromyographically. It is equally self-evident that eye contact when $S$ is smiling (which most of the time requires a face-to-face situation) promotes mimicking - because of the desire to communicate

*Corresponding author: Vladimir J. Konečni, Department of Psychology University of California, San Diego, La Jolla, California 92093-0109, USA, E-mail: vkonecni@ucsd.edu

Received: January 25, 2016; Accepted: January 28, 2016; Published: February 04, 2016

Citation: Konečni VJ (2016) Comprehending Smiles Seldom Requires Embodied Simulation and Felt Emotion. Clin Exp Psychol 2: 114. doi:10.4172/24712701.1000114

Copyright: () 2016 Konečni VJ. This is an open-access article distributed under the terms of the Creative Commons Attribution License, which permits unrestricted use, distribution, and reproduction in any medium, provided the original author and source are credited. 


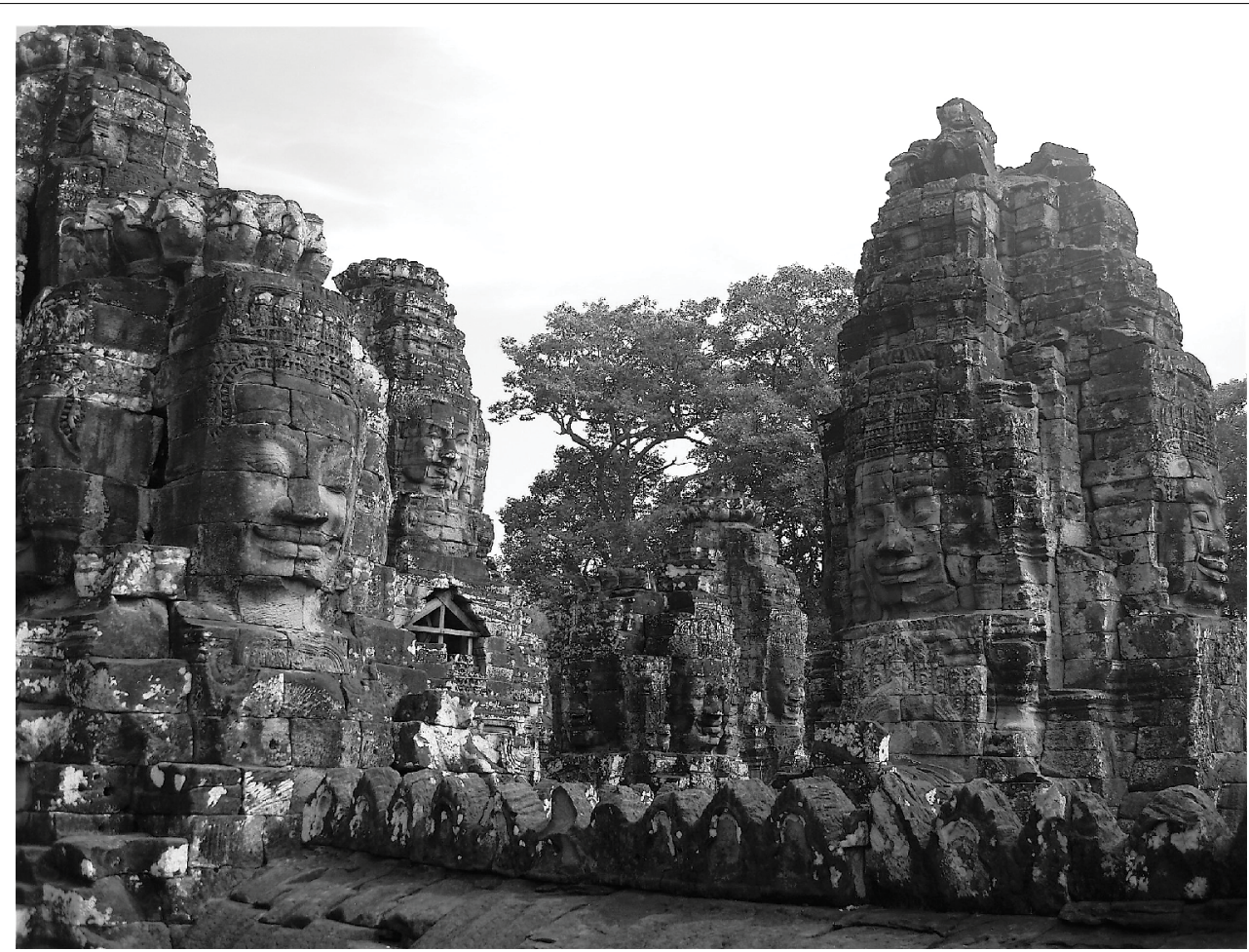

Figure 1: The Bayon, Angkor Thom, Cambodia @ V. J. Konečni, 2010

empathic gladness and because eye contact requires proximity that is usually permitted only to people likely to be favorably disposed to P. Furthermore, it has long been known that facial expression may independently produce a very slight, but statistically significant effect on reports of own emotion [e.g., 3], which may or may not be a genuine report of emotion [cf. 4, 5-6]. But the fact that people can carry out simulation operations under some, probably quite rare, circumstances, does not mean that SIMS is needed or that it is one of the main routes in the comprehension of human expressions - least of all of smiles, and even less so when smiles are treated as a trichotomy that is probably irrelevant from an evolutionary standpoint. SIMS seems to be a construction that is kin to some other questionable recent applications of the concept of "embodiment." Outlining the possible neural loci for the operations that are part of the model, but rarely part of routine human functioning, does not analytically strengthen the position of [1].

Finally, one can legitimately raise several issues about the treatment of the "dominance" smile by [1]. First, who would label Tony Blair's "smile" (Figure 3, left panel, p. 421) as one of "dominance" unless they knew not only his office, but also his allegedly coldly manipulative political style? Second, a dominance smile is unlikely to be mimicked, perhaps because people mimic unpleasant or phony smiles only intentionally, for ridicule, and not spontaneously. Perhaps human beings are not skilled in mimicking falsehood intuitively? Third, how $\mathrm{P}$ responds cognitively and emotionally to a dominance smile clearly depends on the relationship between P and S. Can S be a threat to P? Does $\mathrm{P}$ admire $\mathrm{S}$ ? Is $\mathrm{S}$ a god or just a powerful contemporary?

Such issues touch upon the psychobiologically interesting relationship between the dominance smile and awe as P's moral and aesthetic emotional response [7-9]. They are stunningly exemplified at the Bayon (late 12th-early 13th century, within Angkor Thom, near Siem Reap, Cambodia), where over 200 gigantic smiling faces, sculpted in stone, of the Khmer King Jayavarman VII can be seen (Figure 1).
Dominant? Sardonic? Benevolent? Irritatingly self-assured? Serene? It depends on whether one thinks that the faces are likenesses of Jayavarman VII or portrayals of the Bodhisattiva of Compassion; and on whether $\mathrm{P}$ is a slave-chiseler, a Mahayana Buddhist pilgrim, or a contemporary American or British tourist who is baffled by the King's self-satisfied smile, but welcomes or despises Clinton's and Blair's analogous expressions on the basis of political party affiliation.

\section{References}

1. Niedenthal PM, Mermillod M, Maringer M, Hess U (2010) The simulation of smiles (SIMS) model: Embodied simulation and the meaning of facial expression. Behavioral and Brain Sciences 33: 417-480.

2. Bavelas J, Black A, Lemery CR, Mullett J (1986) 'I show how you feel': Motor mimicry as a communicative act. Journal of Personality and Social Psychology 50: 322-329.

3. Laird JD (1974) Self-attribution of emotion: The effects of expressive behavior on the quality of emotional experience. Journal of Personality and Socia Psychology 29: 475-486.

4. Konečni VJ (1978) Perception and labeling of emotional states in oneself and others. Paper presented in the symposium "New perspectives in the research on emotion" at the 86th Annual Convention of the American Psychological Association, Toronto, Canada.

5. Lanzetta JT, Cartwright-Smith J, Kleck RE (1976) Effects of nonverbal dissimulation on emotional experiences and autonomic arousal. Journal of Personality and Social Psychology 33: 354-370.

6. Sargent-Pollock D (1978) The effects of proprioceptive feedback from facia configuration on emotional experience. Unpublished doctoral dissertation, University of California, San Diego.

7. Keltner D, Haidt J (2003) Approaching awe, a moral, spiritual, and aesthetic emotion. Cognition and Emotion 17: 297-314.

8. Konečni VJ (2005) The aesthetic trinity: Awe, being moved, thrills. Bulletin of Psychology and the Arts 5: 27-44.

9. Konečni VJ (2015) Emotion in painting and art installations. American Journa of Psychology 128: 305-322. 